\title{
Weighing the benefits of hepatocellular carcinoma surveillance against potential harms
}

This article was published in the following Dove Medical Press journal: Journal of Hepatocellular Carcinoma

\author{
Daniel Geh",* \\ Fahd A Rana ${ }^{2, *}$ \\ Helen L Reeves ${ }^{1,3}$ \\ 'Northern Institute for Cancer \\ Research, Newcastle University \\ Medical School, Newcastle upon \\ Tyne, UK; ${ }^{2}$ The Liver Unit, Freeman \\ Hospital, Newcastle upon Tyne, \\ UK; ${ }^{3}$ The Hepatopancreatobiliary \\ Multidisciplinary Team, Newcastle \\ upon Tyne Hospitals NHS Foundation \\ Trust, Newcastle upon Tyne, UK
}

*These authors contributed equally to this work
Correspondence: Helen L Reeves Northern Institute for Cancer Research, Newcastle University Medical School, Framlington Place, Newcastle upon Tyne NE2 $4 \mathrm{HH}$, UK

Tel +44 I 9 I 2084423

Fax+44 I9I 208 430I

Email h.l.reeves@ncl.ac.uk

\begin{abstract}
Hepatocellular carcinoma (HCC) is the most common primary liver cancer and usually occurs in people with liver cirrhosis. Both the incidence and mortality of HCC are increasing worldwide, making it a growing public health issue. HCC diagnosed at an early stage has a far better prognosis than HCC diagnosed at a late stage, mainly because early stage HCC can be treated with potentially curative therapies such as resection and transplantation. This makes surveillance for HCC in patients with liver cirrhosis an important strategy in improving outcomes. Serial measurements of serum alpha fetoprotein (AFP) and abdominal ultrasound (US) are the established methods of surveillance. Surveillance using a combination of these techniques has reasonable sensitivity and specificity and reduces mortality from HCC by varying degrees, depending on the patient population. However, there are potential harms. The main harms result from false-positive and false-negative results. False-positive results commit patients to undergo further, potentially invasive and ultimately unnecessary diagnostic testing - which has both financial and emotional costs. False-negative results can have devastating consequences for patients who later present with more advanced HCC. Obesity is increasingly prevalent and reduces the sensitivity of US in detecting HCC. Obesity-associated non-alcoholic fatty liver disease (NAFLD) presents an additional challenge, where HCC can develop in the absence of cirrhosis. As surveillance with US and AFP is not cost-effective in NAFLD without cirrhosis, it is not advocated. These aspects will be reviewed.
\end{abstract}

Keywords: hepatocellular carcinoma, liver cirrhosis, surveillance, NAFLD, screening

\section{Introduction}

The burden of hepatocellular carcinoma (HCC), accounting for the majority of primary liver cancers and a major complication of liver cirrhosis, is substantial - ranking third in cancer-related deaths worldwide. ${ }^{1}$ In the UK, the incidence of liver cancer has risen considerably over the last decade, with 5,736 new cases in $2015 .{ }^{2}$ Mortality rates have also increased, with $\sim 5,417$ deaths reported in 2016 . This is particularly poignant given that up to $49 \%$ of UK cases of HCC are considered preventable ones. ${ }^{3}$ Many of these patients present with advanced stage disease, where a lack of effective therapies contributes frequently to death within a year. ${ }^{4}$

The term "surveillance" can be defined as the regular implementation of a diagnostic test to individuals at risk of developing a given disease. The principal aim of surveillance programs is to reduce disease-related mortality, the success of which can be influenced by the incidence of the disease in question in the individuals deemed to be at risk - the "target population," the availability of a cheap and efficient test that 
is acceptable to the target population, and the availability of effective treatments if the disease is discovered.

For patients with $\mathrm{HCC}$, where the majority arise in the presence of cirrhosis, there are curative or effective therapies for tumors detected at an earlier stage. Detecting early cancers in patients fit enough to have these therapies can have a major impact on mortality. This review summarizes the changing trends in the epidemiology of liver diseases underlying the development of HCC and focuses on the role of surveillance in patients at risk, detailing the benefits, but also the limitations in different groups of patients.

\section{The changing epidemiology of HCC}

There are several risk factors for liver cirrhosis, including chronic hepatitis B virus (HBV) and hepatitis C virus (HCV) infections, alcohol-related liver disease (ARLD), and obesityrelated non-alcoholic fatty liver disease (NAFLD). Other causes include cholestatic and autoimmune liver diseases, metabolic liver diseases, and cryptogenic cirrhosis. In Asian and African nations, viral etiologies are more common. Their prevalence varies in European countries and in Italy and Spain, where there is a relatively higher HCC incidence and mortality, the differences have been attributed to the prevalence of $\mathrm{HCV}^{5}$ In the UK, where the prevalence of viral hepatitis is lower, ARLD and NAFLD cirrhosis pose a bigger challenge and are responsible for the dramatic increases in both incidence of HCC and mortality attributed to HCC over the last 10 years. ${ }^{4-6}$ Furthermore, data generated by Cancer Research UK suggest that the incidence of primary liver cancer is likely to continue increasing in the UK - at least for the next 20 years, as a result of widespread obesity. ${ }^{7}$

\section{Risk of HCC in cirrhosis}

The pathophysiology of HCC is a multifactorial event. Hepatic inflammation, necrosis, fibrosis, and ongoing regeneration characterize the cirrhotic liver and contribute to HCC development. Approximately 2\%-7\% patients with cirrhosis are reported to develop HCC annually, although the risk attached to different etiologies varies. ${ }^{8}{ }^{8}$ When considering the effectiveness and costs of a surveillance strategy, it is worth considering this variation.

Worldwide, $\sim 80 \%$ of $\mathrm{HCC}$ cases are attributable to chronic HBV and/or HCV infection, especially in the setting of advanced fibrosis and established cirrhosis. ${ }^{10}$ In China, several meta-analyses have demonstrated a 15-20 times greater risk of HCC among HBV-infected individuals compared with the uninfected population. ${ }^{11}$ Moreover, increased incidence and mortality rates of $\mathrm{HCC}$ have been reported in countries with chronic $\mathrm{HBV}$ infection prevalence $>2 \% .^{12}$ The lifetime risk of $\mathrm{HCC}$ among chronic $\mathrm{HBV}$ patients is estimated to be $10 \%-25 \%$. Interestingly, HBV cirrhosis is more strongly associated with HCC in Asia and Africa compared to Western Europe and America, with 5\%-50\% developing HCC in Asia and Africa compared to 3\%-10\% developing HCC in Western Europe and America. ${ }^{12}$ The risk of HCC in treated patients with HBV E-antigen seroconversion or suppressed HBV replication is lower, but not eliminated. ${ }^{13}$ Prospective studies have also shown a markedly increased risk of HCC in HCV-infected patients. In Japan, $70 \%$ of cases diagnosed with $\mathrm{HCC}$ over the last 10 years were $\mathrm{HCV}$ antibody (HCV Ab)-positive. ${ }^{14}$ In Korea, $10 \%-20 \%$ of HCC patients are positive for $\mathrm{HCV} \mathrm{Ab}$. A meta-analysis of case-control studies suggested that individuals positive for $\mathrm{HCV} \mathrm{Ab}$ have a 17-fold increased risk of developing HCC compared with those negative for $\mathrm{HCV} \mathrm{Ab.}{ }^{15}$ Similar to patients with $\mathrm{HBV}$, patients treated successfully for $\mathrm{HCV}$ are also growing in number and while viral clearance markedly reduces their risk, again, it is not eliminated. ${ }^{16}$

The 5-year cumulative risk of HCC in an individual with ARLD cirrhosis is reported to be $\sim 8 \% .{ }^{17}$ While this is less than that for patients with viral hepatitis, it is an important cause of HCC in regions where alcohol excess is common. ${ }^{4}$

Consequent to a global epidemic of obesity, NAFLD now affects a large proportion of the world population and both its incidence and prevalence are increasing. ${ }^{6}$ Although only a minority of patients with NAFLD progress to cirrhosis, NAFLD is now so widespread that it has become the commonest cause of cirrhosis in western nations. ${ }^{18-20}$ The risk of HCC in NAFLD cirrhosis is estimated at $2.6 \%$ and NAFLD cirrhosis now typically accounts for $10 \%-14 \%$ of HCC cases in Europe or North America. ${ }^{21-23}$ In Northern England, the number of HCC cases referred to the tertiary center in Newcastle upon Tyne has increased over tenfold with NAFLD accounting for $35 \%$ of cases. ${ }^{4}$

Cumulative evidence on which the recommendations in the recently published European Association for Study of the Liver (EASL) guidelines were based suggests costeffectiveness where the incidence of HCC in cirrhotic patients exceeds $1.5 \%$ per year - which includes all cirrhotic patients regardless of their underlying etiology. ${ }^{24}$

\section{Risk of HCC in non-cirrhotic patients}

A large cohort study published by Giannini et al in 2013 reported that 52 of 3,027 cases $(1.7 \%)$ of $\mathrm{HCC}$ were found in non-cirrhotic livers. ${ }^{25}$ Notably, these patients were more likely to present at a more advanced tumor stage, associated 
with a poorer prognosis. Therefore, while cirrhosis is clearly the most important risk factor for HCC development, there are some identifiable groups of patients without cirrhotic liver disease who have an elevated risk of developing HCC. As these patients may have better preserved liver function with more opportunities for curative interventions for early stage disease, cost-effectiveness may justify surveillance in some of these groups even if the incidence is $<1.5 \%$. Hence there is a need to consider these groups carefully.

HBV can have oncogenic effects as a consequence of its integration into the human genome, and therefore, patients with chronic infection have an elevated risk of developing HCC even in the absence of cirrhosis. The risk is reportedly elevated in the presence of higher levels of HBV replication and is higher in males and also in Asian and African countries, as compared to western countries. ${ }^{26}$ For patients with chronic $\mathrm{HCV}$, those with more advanced or bridging fibrosis falling short of cirrhosis have a higher risk of HCC. ${ }^{27}$ For these groups of patients with viral hepatitis without cirrhosis, surveillance is justifiable.

The epidemiology and natural history of NAFLD-HCC are presently unfolding, with the numbers of patients with NAFLD-HCC without cirrhosis steadily increasing and reported to be as high as $25 \%-45 \%$ in some series. ${ }^{4,28}$ While these numbers are substantial, the population at risk is very large and an individual patients' risk of developing HCC in the presence of non-cirrhotic NAFLD is actually very small. ${ }^{29}$ In patients with type 2 diabetes, who have an elevated risk compared to the general population, the risk is still smaller - estimated to be in the region of $0.8 / 1,000$ patient-years. ${ }^{30}$ Consequently, surveillance in NAFLD patients without cirrhosis, or patients with obesity or type 2 diabetes in the absence of cirrhosis, is not advocated.

\section{Benefits of surveillance}

As outlined above, HCC is a substantial cause of death worldwide, with the majority of cases presenting at advanced and incurable stages. As there are effective curative therapies for early stage cases, and the majority of cases arise in individuals with a known predisposing condition, an acceptable test, applied regularly to a fit target population known to have an elevated risk could potentially have a major positive impact on mortality.

The tests most commonly used for HCC surveillance include a serum measurement of tumor marker alpha fetoprotein (AFP) and an abdominal ultrasonography (US). ${ }^{24}$ In a population-based Chinese study targeting a region with a high prevalence of $\mathrm{HBV}$, all the villages in the region were randomized either to receiving US and AFP measurements every 6 months or to "no surveillance." Despite a compliance rate of only $55 \%$ in the surveillance arm, HCC mortality was reduced by $37 \%$ - as a result of a greater detection of earlier stage lesions and a higher rate of curative resection. ${ }^{31}$ This was a randomized controlled trial, providing the strongest level of evidence in favor of a benefit for HCC surveillance. While highly encouraging, the study by Zhang et al described above is the only published randomized controlled trial addressing the benefit of surveillance vs no surveillance. It was population based in a region with a significant mortality attributed to HBV-HCC, and its positive outcome should not necessarily be assumed to be representative of other target populations - perhaps where the relative risk in the target population, the fitness to undergo curative treatments, and the sensitivity of US and AFP as diagnostic tests may be lower. Performing additional RCTs may well have been worthwhile from a costeffective viewpoint, but the ethical dilemma of randomizing patients at risk to a non-surveillance arm has been a major hindrance. Instead, there have been other types of studies, including cohort studies exploring the impact of surveillance in individuals with cirrhosis. ${ }^{32,33}$ In addition, there have been high-quality studies in cirrhotic patients, comparing 3-, 6-, and 12-month surveillance intervals. ${ }^{34,35}$ There have also been cost utility analyses. A UK-based study using a decision analytic model suggested that 6-monthly US had an incremental costeffectiveness ratio of around $£ 30,000$ per quality-adjusted life year (QALY). ${ }^{36}$ Adding AFP to 6-monthly US reportedly increased the cost to $£ 60,100$ per QALY, as the additional pick up rate of $6 \%-8 \%$ was thought not to counteract the increased rate of false-positive results and additional diagnostic testing. ${ }^{37}$ North American studies have modeled US with or without AFP to cost around $\$ 30,000$ per QALY. ${ }^{38,39}$ Annual computed tomography (CT) and magnetic resonance image (MRI) surveillance were estimated to cost between $\$ 25,323$ and \$50,000 and $\$ 118,000$ per QALY, respectively. ${ }^{38,39}$

In combination, these studies have largely reinforced the benefit of surveillance in cirrhotic patients, and the 6-month interval with US, possibly in conjunction with AFP, is widely promoted. ${ }^{40-42}$ International guidelines on the surveillance of HCC are summarized in Table 1. The benefits of surveillance are summarized in Table 2.

\section{The limitations of surveillance and its potential harms}

Much of the criticism of surveillance programs stem from the lack of evidence underpinning its widespread application in individuals where the true efficacy and cost-effectiveness 
Table I Summary of current international guidelines on HCC surveillance

\begin{tabular}{|l|l|l|l|}
\hline Guidelines & Surveillance population & Surveillance modality & Surveillance interval \\
\hline AASLD 201840 & $\begin{array}{l}\text { All patients with liver cirrhosis except patients with Child-Pugh stage } \\
\text { C cirrhosis unless on transplant waiting list }\end{array}$ & US \pm AFP & 6 months \\
\hline APASL 201741 & $\begin{array}{l}\text { All patients with cirrhosis } \\
\text { Chronic HBV carriers without cirrhosis } \\
\text { - Asian females }>50 \text { years } \\
\text { - Asian males }>40 \text { years } \\
\text { - Africans }>20 \text { years } \\
\text { - Family history of HCC }\end{array}$ & US + AFP & 6 months \\
\hline EASL 201824 & $\begin{array}{l}\text { Cirrhosis Child-Pugh stage A and B } \\
\text { Cirrhosis Child-Pugh stage C awaiting liver transplant } \\
\text { Chronic HBV without cirrhosis at intermediate (I0-I7) or high risk } \\
(\geq 18) \text { of HCC according to PAGE-B score } \\
\text { Non-cirrhotic patients with Metavir F3 fibrosis regardless of etiology }\end{array}$ & US & 6 months \\
\hline ESMO 201842 & $\begin{array}{l}\text { All patients with cirrhosis as long as liver function and comorbidities } \\
\text { allow curative or palliative treatment } \\
\text { Chronic HBV and HCV carriers with Metavir F3 fibrosis } \\
\text { Asian chronic HBV carriers with serum HBV-DNA above 10,000 } \\
\text { copies/mL }\end{array}$ & US AFP & 6 months \\
\hline
\end{tabular}

Abbreviations: AASLD, American Association for the Study of Liver Disease; AFP, alpha fetoprotein; APASL, Asian Pacific Association for the Study of the Liver; EASL, European Association for the Study of the Liver; ESMO, European Society for Medical Oncology; HBV, hepatitis B virus; HCC, hepatocellular carcinoma; HCV, hepatitis C virus; PAGE-B score, Platelets, Age, Gender, Hepatitis B; US, ultrasound.

Table 2 The benefits vs limitations and risks of HCC surveillance

\begin{tabular}{|c|c|}
\hline Benefits of surveillance & Limitations and potential harms of surveillance \\
\hline $\begin{array}{l}\text { Allows diagnosis of } \mathrm{HCC} \text { at an earlier } \\
\text { stage }\end{array}$ & $\begin{array}{l}\text { Limitations in study design of current evidence such as lack of randomized controlled trials and lead } \\
\text { time bias }\end{array}$ \\
\hline Reduces HCC mortality & $\begin{array}{l}\text { Financial cost } \\
\text { - Questionable cost-effectiveness } \\
\text { - Cost to health care system } \\
\text { - Cost to patients }\end{array}$ \\
\hline Increases the rate of curative resection & $\begin{array}{l}\text { Limitations of surveillance tests } \\
\text { - US - operator dependent and sensitivity reduces in patients with central obesity } \\
\text { - AFP - poor sensitivity and poor specificity leading to false-positive and false-negative results }\end{array}$ \\
\hline $\begin{array}{l}\text { US allows detection of other } \\
\text { complications of cirrhosis such as } \\
\text { ascites and portal vein thrombosis }\end{array}$ & $\begin{array}{l}\text { Up to } 5 \% \text { of patients have false-positive results } \\
\text { Harms of false-positive results } \\
\text { - Radiation exposure with cross-sectional imaging } \\
\text { - Contrast risk } \\
\text { - Risk of invasive procedures such as liver biopsy } \\
\text { - Psychosocial harm to patient and family }\end{array}$ \\
\hline $\begin{array}{l}\text { Unarguable value in well-defined target } \\
\text { populations who have a high incidence of } \\
\text { HCC and are fit for intervention }\end{array}$ & $\begin{array}{l}\text { Although HCC in NAFLD without cirrhosis is increasingly common, the target population is so large, } \\
\text { and the incidence within the population is so small, surveillance in NAFLD patients without cirrhosis } \\
\text { is not cost-effective and is not advocated }\end{array}$ \\
\hline
\end{tabular}

Abbreviations: AFP, alpha fetoprotein; HCC, hepatocellular carcinoma; NAFLD, non-alcoholic fatty liver disease; US, abdominal ultrasound.

are unknown. There are numerous supportive studies, but a well-recognized weakness of cohort studies or case series is that they often fail to take into account the impact of lead time and length time bias. Lead time bias refers to an apparent improvement of survival simply because the diagnosis of cancer is made earlier. Length time bias can occur if there is an over-representation of patients with slower-growing tumors, if those with the most aggressive and rapidly growing tumors present and die within the surveillance interval and their data are not captured. While these are valid criticisms, correction formulas can be applied and a retrospective casecontrol study from Italy recently reported that survival benefit beyond 3 years could confidently be attributed to successful surveillance rather than lead time bias. ${ }^{43}$ 
The other factor not always appreciated is the impact of being in a surveillance program on individual patients. There are cost implication for patients, not just health care bodies, in terms of time, finances for travel or parking, as well as hospital visit-related stress. Those in whom HCCs are detected at an early stage who then undergo curative or life-prolonging therapies do benefit overall, but this needs to be interpreted alongside an appreciation of the negative impact and burden of tests in individuals in whom cancers are not detected, or in fact where cancers are detected, but at a stage too late to be of benefit.

For those undergoing surveillance, abdominal US is a safe and noninvasive test that is acceptable to patients. However, it is widely appreciated that HCC can be difficult to detect in cirrhotic livers and its usefulness is operator dependent. ${ }^{44,45}$ Detection in centrally obese individuals is also more challenging, and the test is not as sensitive in these individuals. ${ }^{46}$ However, its cost is relatively modest, with an overall sensitivity that ranges from $58 \%$ to $89 \%$ and a specificity $>90 \%$ - which is deemed acceptable for a surveillance test. ${ }^{47}$ US also has the capacity to detect other complications of cirrhosis that may benefit from earlier intervention - such as subclinical ascites or a portal vein thrombosis.

Serum AFP has been used for decades but has poorer sensitivity for the detection of early lesions and is in fact no longer recommended by the EASL guidelines as a surveillance tool. ${ }^{24}$ The recently revised AASLD and Asian Pacific Association for the Study of the Liver guidelines suggest that it may have a role alongside US, although advises noting the rate of increase rather than just the absolute level, as the latter can be raised in some individuals with chronic liver disease who do not have $\mathrm{HCC}$, contributing to the test's poor specificity. ${ }^{40,41}$ Despite these negative attributes, the test is cheap and its addition to US reportedly facilitates the detection of an additional $6 \%-8 \%$ of cases overall. ${ }^{48} \mathrm{~A}$ recent meta-analysis including 32 studies reported US sensitivity of $84 \%$ for all stages of HCC, although this percentage was notably higher for larger cancers and significantly lower for early stage cases. ${ }^{49}$ This meta-analysis reported that US with and without AFP detected early stage HCC with $63 \%$ and $45 \%$ sensitivity, respectively. Thus, the combination is most likely superior to US alone and remains standard practice in many centers. ${ }^{49}$

In addition to patient inconvenience and cost, the added harms of false-positive tests should also be appreciated. An US scan detecting a small suspicious nodule, or a slightly raised AFP, will result in further investigations. A CT scan to visualize and further characterize a suspected lesion leads to radiation exposure and requires the use of intravenous contrast, with an injection and potential renal toxicity. An MRI scan may be considered as an alternative or in addition and has no irradiation exposure. However, a contrast injection is still required, and there is still a small risk to renal function. In addition, many patients find MRI scans distressing as they take more time to complete, and the "tunnel-like" environment in which the patient is placed often causes distress and anxiety. Patients may also be subjected to invasive procedures such as liver biopsy in order to sample a suspicious lesion, if scans are insufficient to characterize it confidently.

Having the reassurance that a nodule is regenerative, or dysplastic requiring heightened observation rather than an HCC requiring intervention, can be very informative. Thus, while some may class an additional scan or biopsy that confirms a non-cancerous lesion as a "surveillance harm event," both the clinician and the patient may well value that information, rather than regard it as resulting from an "unnecessary" investigation. Not to be forgotten though is that there are also risks - albeit small - associated with liver biopsy. These include bleeding, which very occasionally can be life threatening. ${ }^{44,45} \mathrm{~A}$ decision to biopsy a lesion in a cirrhotic liver should be carefully considered within a multidisciplinary team. ${ }^{24}$

While we generally accept, based on guidelines, that surveillance is recommended and that false-positive events will trigger additional investigations, studies over the last decade have estimated that every year up to $5 \%$ of patients undergoing HCC surveillance will have a false-positive test warranting further investigations..$^{34,50}$ Therefore, the number and associated costs are high. A recent report by Atiq et al suggests that false-positive harm events are rising rather than falling. ${ }^{51}$ The study included 680 cirrhotic patients of which $11.5 \%$ (78) developed HCC over a 3-year period. Forty-eight (61.5\%) of the HCCs were identified by using surveillance, including $43.8 \%$ by US, $31.2 \%$ with AFP and the remainder (25\%) by a combination of the two. Surveillance harm events over the same period, defined largely as unnecessary testing, were identified in 187 cohort patients, equating to $\sim 9 \%$ per year and adding significantly to the cost of each true HCC detected. Of note, US-related harms were more frequent than AFP-related harms. ${ }^{51}$ As the prevalence of obesity and poor sonar subjects increases, the rising costs associated with false-positive tests may have a negative impact on cost-benefit analyses and ultimately result in the practice being simply too expensive unless surveillance tools for the at-risk populations improve.

Another surveillance harm is that of false-negative imaging. A recent study evaluated 352 patients who were being 
assessed for liver transplant for indications other than HCC. Individuals underwent US, and this was compared with $\mathrm{CT}$ or MRI. Patients with body mass index (BMI) $\geq 30 \mathrm{~kg} / \mathrm{m}^{2}$ had an US sensitivity for HCC detection of 0.76 vs 0.87 for BMI $<30 \mathrm{~kg} / \mathrm{m}^{2}(P=0.01)$. US sensitivity was further decreased in patients with NAFLD-cirrhosis vs other etiologies $(0.59$ vs $0.84, P=0.003) .{ }^{52}$ This study supports the deteriorating sensitivity of the tools we use in the fastest growing at-risk population (obese individuals with NAFLD), and as a consequence, inadequate or false-negative imaging is likely to increase. A cancer diagnosis is very commonly associated with fear and anxiety, and a late or missed diagnosis in a patient entered into a surveillance program adds anger and disappointment to the psychosocial harm, for both the patient and their families. The limitations of surveillance are summarized in Table 2.

\section{HCC surveillance in developing countries}

Around $80 \%$ of HCC occurs in developing countries due to the high prevalence of $\mathrm{HBV}$ infection and aflatoxin $\mathrm{B} 1$ exposure. ${ }^{53,54}$ The prognosis of $\mathrm{HCC}$ is significantly worse in these countries compared to developed ones, owing to lack of detection of $\mathrm{HBV}$, lack of HCC surveillance programs, late diagnosis of cancers, and limited access to treatments. ${ }^{55,56}$ Recognizing the risk to $\mathrm{HBV}$-infected individuals, but without the resource to implement more costly surveillance initiatives, AFP measurement alone has been recommended for HCC surveillance in Sub-Saharan Africa. ${ }^{57}$ The success of strategies such as these is not easy to evaluate, but in resource-limited counties with a high incidence of $\mathrm{HCC}$, this approach may well extend survival if affected individuals are offered treatments.

\section{Summary and recommendations}

The evidence available supports the use of HCC surveillance with a combination of 6-monthly US scan and serum AFP in individuals at higher risk of developing HCC. The measure of success in terms of reduced mortality and life years saved varies in different target populations, reflecting the level of risk, the fitness of the individuals, and the effectiveness of the tools used - each of which vary in the context of the different etiologies predisposing to HCC. The following factors should be considered by physicians directing surveillance: weighing up for each individual his or her risk of developing HCC, the likelihood of being able to offer him or her life-prolonging therapy, alongside the burden of surveillance for both the patient and the health care provider. If there is a good case for offering surveillance, this - as well as the limitations - should be explained to the individuals and their consent to proceed obtained.

The recent EASL guideline recommends surveillance in all cirrhotic patients with preserved liver function graded as Child-Pugh stage A or B, as well as in patients of Child-Pugh stage $\mathrm{C}$ awaiting liver transplantation. ${ }^{24}$ For patients with $\mathrm{HBV}$ without cirrhosis, assessing risk with the PAGE-B score is advised, offering surveillance to those with a score $>9 .{ }^{24}$ These tend to be older, male patients with reduced platelet number - age, sex, and platelet count being the three factors on which the score is based. Surveillance is also recommended for individuals with advanced fibrosis (Metavir F3) falling short of cirrhosis regardless of etiology. In each of these patient groups, there is no evidence to support withdrawal of surveillance beyond a certain age, although withdrawal based on futility should be explained to patients developing comorbidities or frailty that would limit the application of life-prolonging therapies.

Although one of the most rapidly growing groups of patients with HCC are those with non-cirrhotic NAFLD, cost-effective analyses do not support surveillance in those with NAFLD who do not have cirrhosis or advanced fibrosis. Continued efforts to stratify risk in these individuals - perhaps including factors such as age and sex in conjunction with NAFLD-HCC risks such as PNPLA3 genotype - alongside efforts to identify more sensitive and specific tools relevant to these patients may change this recommendation in future years..$^{58,59}$

\section{Disclosure}

The authors report no conflicts of interest in this work.

\section{References}

1. Golabi P, Fazel S, Otgonsuren M, Sayiner M, Locklear CT, Younossi ZM. Mortality assessment of patients with hepatocellular carcinoma according to underlying disease and treatment modalities. Medicine. 2017;96(9):e5904.

2. Cancer Research UK [webpage on the Internet]. Liver cancer incidence statistics. Available from: https://www.cancerresearchuk.org/healthprofessional/cancer-statistics/statistics-by-cancer-type/liver-cancer/ incidence\#heading-Zero. Accessed September 26, 2018.

3. Cancer Research UK [webpage on the Internet]. Liver cancer mortality statistics. Available from: https://www.cancerresearchuk.org/healthprofessional/cancer-statistics/statistics-by-cancer-type/liver-cancer/ mortality\#heading-Zero. Accessed September 26, 2018.

4. Dyson J, Jaques B, Chattopadyhay D, et al. Hepatocellular cancer: the impact of obesity, type 2 diabetes and a multidisciplinary team. J Hepatol. 2014;60(1):110-117.

5. Petrick JL, Braunlin M, Laversanne M, Valery PC, Bray F, McGlynn KA. International trends in liver cancer incidence, overall and by histologic subtype, 1978-2007. Int J Cancer. 2016;139(7):1534-1545.

6. Siegel AB, Zhu AX. Metabolic syndrome and hepatocellular carcinoma: two growing epidemics with a potential link. Cancer. 2009;115(24):5651-5661. 
7. Smittenaar CR, Petersen KA, Stewart K, Moitt N. Cancer incidence and mortality projections in the UK until 2035. Br J Cancer. 2016;115(9): 1147-1155.

8. Forner A, Reig M, Bruix J. Hepatocellular carcinoma. Lancet. 2018;391(10127):1301-1314.

9. Flemming JA, Yang JD, Vittinghoff E, Kim WR, Terrault NA. Risk prediction of hepatocellular carcinoma in patients with cirrhosis: the ADRESS-HCC risk model. Cancer. 2014;120(22):3485-3493.

10. Yang JD, Roberts LR. Hepatocellular carcinoma: a global view. Nat Rev Gastroenterol Hepatol. 2010;7(8):448-458.

11. Shi J, Zhu L, Liu S, Xie WF. A meta-analysis of case-control studies on the combined effect of hepatitis $\mathrm{B}$ and $\mathrm{C}$ virus infections in causing hepatocellular carcinoma in China. Br J Cancer. 2005;92(3): 607-612.

12. McGlynn KA, London WT. The global epidemiology of hepatocellular carcinoma: present and future. Clin Liver Dis. 2011;15(2):223-243.

13. Papatheodoridis GV, Chan HL, Hansen BE, Janssen HL, Lampertico P. Risk of hepatocellular carcinoma in chronic hepatitis B: assessment and modification with current antiviral therapy. $J$ Hepatol. 2015;62(4):956-967.

14. Fasani P, Sangiovanni A, De Fazio C, et al. High prevalence of multinodular hepatocellular carcinoma in patients with cirrhosis attributable to multiple risk factors. Hepatology. 1999;29(6):1704-1707.

15. Donato F, Tagger A, Gelatti U, et al. Alcohol and hepatocellular carcinoma: the effect of lifetime intake and hepatitis virus infections in men and women. Am J Epidemiol. 2002;155(4):323-331.

16. Morgan RL, Baack B, Smith BD, Yartel A, Pitasi M, Falck-Ytter Y. Eradication of hepatitis $\mathrm{C}$ virus infection and the development of hepatocellular carcinoma: a meta-analysis of observational studies. Ann Intern Med. 2013;158(5 Pt 1):329-337.

17. Fattovich G, Stroffolini T, Zagni I, Donato F. Hepatocellular carcinoma in cirrhosis: incidence and risk factors. Gastroenterology. 2004;127(5 Suppl 1):S35-S50

18. Younossi ZM, Koenig AB, Abdelatif D, Fazel Y, Henry L, Wymer M. Global epidemiology of nonalcoholic fatty liver disease-Meta-analytic assessment of prevalence, incidence, and outcomes. Hepatology. 2016;64(1):73-84.

19. Williams CD, Stengel J, Asike MI, et al. Prevalence of nonalcoholic fatty liver disease and nonalcoholic steatohepatitis among a largely middleaged population utilizing ultrasound and liver biopsy: a prospective study. Gastroenterology. 2011;140(1):124-131.

20. Younossi Z, Anstee QM, Marietti M, et al. Global burden of NAFLD and NASH: trends, predictions, risk factors and prevention. Nat Rev Gastroenterol Hepatol. 2018;15(1):11-20.

21. Ascha MS, Hanouneh IA, Lopez R, Tamimi TA, Feldstein AF, Zein $\mathrm{NN}$. The incidence and risk factors of hepatocellular carcinoma in patients with nonalcoholic steatohepatitis. Hepatology. 2010;51(6): 1972-1978.

22. Park JW, Chen M, Colombo M, et al. Global patterns of hepatocellular carcinoma management from diagnosis to death: the bridge study. Liver Int. 2015;35(9):2155-2166.

23. Younossi ZM, Otgonsuren M, Henry L, et al. Association of nonalcoholic fatty liver disease (NAFLD) with hepatocellular carcinoma (HCC) in the United States from 2004 to 2009. Hepatology. 2015;62(6): 1723-1730.

24. European Association for the Study of the Liver; Galle PR, Forner A, Llovet JM, et al. EASL clinical practice guidelines: management of hepatocellular carcinoma. J Hepatol. 2018;69(1):182-236.

25. Giannini EG, Marenco S, Bruzzone L, et al. Hepatocellular carcinoma in patients without cirrhosis in Italy. Dig Liver Dis. 2013;45(2): 164-169.

26. Yang HI, Yuen MF, Chan HL, et al. Risk estimation for hepatocellular carcinoma in chronic hepatitis B (REACH-B): development and validation of a predictive score. Lancet Oncol. 2011;12(6):568-574.

27. Lok AS, Seeff LB, Morgan TR, et al. Incidence of hepatocellular carcinoma and associated risk factors in hepatitis C-related advanced liver disease. Gastroenterology. 2009;136(1):138-148.
28. Piscaglia F, Svegliati-Baroni G, Barchetti A, et al. Clinical patterns of hepatocellular carcinoma in nonalcoholic fatty liver disease: a multicenter prospective study. Hepatology. 2016;63(3):827-838.

29. Kawamura Y, Arase Y, Ikeda K, et al. Large-scale long-term follow-up study of Japanese patients with non-alcoholic fatty liver disease for the onset of hepatocellular carcinoma. Am J Gastroenterol. 2012;107(2): 253-261.

30. Morling JR, Fallowfield JA, Guha IN, et al. Clinically significant chronic liver disease in people with type 2 diabetes: the Edinburgh type 2 Diabetes Study. QJM. 2016;109(4):249-256.

31. Zhang BH, Yang BH, Tang ZY. Randomized controlled trial of screening for hepatocellular carcinoma. J Cancer Res Clin Oncol. 2004;130(7):417-422.

32. Trevisani F, Santi V, Gramenzi A, et al. Surveillance for early diagnosis of hepatocellular carcinoma: is it effective in intermediate/advanced cirrhosis? Am J Gastroenterol. 2007;102(11):2448-2457.

33. Singal A, Volk ML, Waljee A, et al. Meta-analysis: surveillance with ultrasound for early-stage hepatocellular carcinoma in patients with cirrhosis. Aliment Pharmacol Ther. 2009;30(1):37-47.

34. Trinchet JC, Chaffaut C, Bourcier V, et al. Ultrasonographic surveillance of hepatocellular carcinoma in cirrhosis: a randomized trial comparing 3- and 6-month periodicities. Hepatology. 2011;54(6):1987-1997.

35. Santi V, Trevisani F, Gramenzi A, et al. Semiannual surveillance is superior to annual surveillance for the detection of early hepatocellular carcinoma and patient survival. J Hepatol. 2010;53(2):291-297.

36. Thompson Coon J, Rogers G, Hewson P, et al. Surveillance of cirrhosis for hepatocellular carcinoma: A cost-utility analysis. $\mathrm{Br} J$ Cancer. 2008;98(7):1166-1175.

37. Zhang B, Yang B. Combined $\alpha$ fetoprotein testing and ultrasonography as a screening test for primary liver cancer. J Med Screen. 1999;6(2):108-110.

38. Andersson KL, Salomon JA, Goldie SJ, Chung RT. Cost effectiveness of alternative surveillance strategies for hepatocellular carcinoma in patients with cirrhosis. Clin Gastroenterol Hepatol. 2008;6(12): $1418-1424$.

39. Arguedas MR, Chen VK, Eloubeidi MA, Fallon MB. Screening for hepatocellular carcinoma in patients with hepatitis $\mathrm{C}$ cirrhosis: A costutility analysis. Am J Gastroenterol. 2003;98(3):679-690.

40. Heimbach JK, Kulik LM, Finn RS, et al. AASLD guidelines for the treatment of hepatocellular carcinoma. Hepatology. 2018;67(1):358-380.

41. Omata M, Cheng AL, Kokudo N, et al. Asia-Pacific clinical practice guidelines on the management of hepatocellular carcinoma: a 2017 update. Hepatol Int. 2017;11(4):317-370.

42. Vogel A, Cervantes A, Chau I, et al. Hepatocellular carcinoma: ESMO clinical practice guidelines for diagnosis, treatment and follow-up. Ann Oncol. 2018;29(Supplement_4):iv238-iv255.

43. Cucchetti A, Trevisani F, Pecorelli A, et al. Estimation of lead-time bias and its impact on the outcome of surveillance for the early diagnosis of hepatocellular carcinoma. J Hepatol. 2014;61(2):333-341.

44. Bruix J, Sherman M; Practice Guidelines Committee, American Association for the Study of Liver Diseases. Management of hepatocellular carcinoma. Hepatology. 2005;42(5):1208-1236.

45. Bruix J, Sherman M; American Association for the Study of Liver Diseases. Management of hepatocellular carcinoma: an update. Hepatology. 2011;53(3):1020-1022.

46. Del Poggio P, Olmi S, Ciccarese F, et al. Factors that affect efficacy of ultrasound surveillance for early stage hepatocellular carcinoma in patients with cirrhosis. Clin Gastroenterol Hepatol. 2014;12(11): 1927-1933.

47. Bolondi L. Screening for hepatocellular carcinoma in cirrhosis. J Hepatol. 2003;39(6):1076-1084.

48. Biselli M, Conti F, Gramenzi A, et al. A new approach to the use of $\alpha$-fetoprotein as surveillance test for hepatocellular carcinoma in patients with cirrhosis. Br J Cancer. 2015;112(1):69-76.

49. Tzartzeva K, Obi J, Rich NE, et al. Surveillance imaging and alpha fetoprotein for early detection of hepatocellular carcinoma in patients with cirrhosis: a meta-analysis. Gastroenterology. 2018;154(6):1706-1718. 
50. Trinchet JC, Bourcier V, Chaffaut C, et al. Complications and competing risks of death in compensated viral cirrhosis (ANRS CO12 CirVir prospective cohort). Hepatology. 2015;62(3):737-750.

51. Atiq O, Tiro J, Yopp AC, et al. An assessment of benefits and harms of hepatocellular carcinoma surveillance in patients with cirrhosis. Hepatology. 2017;65(4):1196-1205.

52. Samoylova ML, Mehta N, Roberts JP, Yao FY. Predictors of ultrasound failure to detect hepatocellular carcinoma. Liver Transpl. 2018;24(9):1171-1177.

53. Ferlay J, Shin HR, Bray F, Forman D, Mathers C, Parkin DM. Estimates of worldwide burden of cancer in 2008: GLOBOCAN 2008. Int $J$ Cancer. 2010;127(12):2893-2917.

54. Kew MC. Synergistic interaction between aflatoxin B1 and hepatitis B virus in hepatocarcinogenesis. Liver Int. 2003;23(6):405-409.
55. Kew MC. Hepatocellular carcinoma in developing countries: prevention, diagnosis and treatment. World J Hepatol. 2012;4(3):99-104.

56. Ladep NG, Lesi OA, Mark P, et al. Problem of hepatocellular carcinoma in West Africa. World J Hepatol. 2014;6(11):783-792.

57. Ferenci P, Fried M, Labrecque D, et al. World gastroenterology organisation guideline. hepatocellular carcinoma (HCC): a global perspective. J Gastrointestin Liver Dis. 2010;19(3):311-317.

58. Hassan MM, Kaseb A, Etzel CJ, et al. Genetic variation in the PNPLA3 gene and hepatocellular carcinoma in USA: Risk and prognosis prediction. Mol Carcinog. 2013;52(S1):139-147.

59. Liu YL, Patman GL, Leathart JB, et al. Carriage of the PNPLA3 rs738409 $\mathrm{C}>\mathrm{G}$ polymorphism confers an increased risk of nonalcoholic fatty liver disease associated hepatocellular carcinoma. J Hepatol. 2014;61(1):75-81.
Journal of Hepatocellular Carcinoma

\section{Publish your work in this journal}

The Journal of Hepatocellular Carcinoma is an international, peerreviewed, open access journal that offers a platform for the dissemination and study of clinical, translational and basic research findings in this rapidly developing field. Development in areas including, but not limited to, epidemiology, vaccination, hepatitis therapy, pathology and

\section{Dovepress}

molecular tumor classification and prognostication are all considered for publication. The manuscript management system is completely online and includes a very quick and fair peer-review system, which is all easy to use. Visit http://www.dovepress.com/testimonials.php to read real quotes from published authors.

Submit your manuscript here: https://www.dovepress.com/journal-of-hepatocellular-carcinoma-journal 